07

\title{
Повышение степени циркулярной поляризации спиновых светоизлучающих диодов путем обработки в парах селена
}

\author{
(c) М.В. Дорохин ${ }^{1}$, П.Б. Дёмина ${ }^{1}$, А.В. Буданов ${ }^{2}$, Ю.Н. Власов ${ }^{2}$, Г.И. Котов ${ }^{2}$, А.В. Здоровейщев ${ }^{1}$, \\ В.Н. Трушин ${ }^{1}$, Б.Н. Звонков ${ }^{1}$ \\ ${ }^{1}$ Научно-исследовательский физико-технический институт Нижегородского государственного университета \\ им. Н.И. Лобачевского, Нижний Новгород, Россия \\ ${ }^{2}$ Воронежский государственный университет инженерных технологий, Воронеж, Россия \\ E-mail: dorokhin@nifti.unn.ru
}

Поступило в Редакцию 14 ноября 2018 г.

В окончательной редакции 13 декабря 2018 г.

Принято к публикации 13 декабря 2018 г.

\begin{abstract}
Сформированы спиновые светоизлучающие диоды на основе гетероструктур InGaAs/GaAs с ферромагнитным инжектором CoPt. Показано, что обработка поверхности структур в парах селена перед нанесением CoPt-контакта позволяет повысить степень циркулярной поляризации излучения диода (по сравнению с исходной необработанной структурой). Повышение степени поляризации связывается с уменьшением спиновой релаксации на границе металлического и полупроводникового слоев вследствие пассивации поверхности и уменьшения плотности поверхностных электронных состояний в результате обработки в парах селена.
\end{abstract}

DOI: 10.21883/PJTF.2019.05.47400.17588

Спиновые светоизлучающие диоды с контактом металл/туннельно-тонкий диэлектрик/полупроводник являются базовым элементом спинтроники [1-3]. Этот элемент реализует фундаментальный принцип электрической инжекции спин-поляризованных носителей заряда из намагниченного ферромагнитного слоя в полупроводниковую излучающую структуру (спиновой инжекции) [4]. К настоящему моменту спиновая инжекция исследована экспериментально и описана в ряде теоретических работ [1-5].

Вопросом, который до сих пор остается недостаточно изученным, является спиновая релаксация на гетерограницах металл/диэлектрик и диэлектрик/полупроводник. В большинстве работ принимается гипотеза идеальной границы раздела, при переносе через которую степень спиновой поляризации носителей практически не претерпевает изменений [1-5]. Между тем на границах раздела всегда присутствует диффузия атомов металла и полупроводника [6,7], а также комплекс дефектных центров, обусловливающих наличие поверхностных электронных состояний [6,7]. Эти дефектные центры обусловливают спиновую релаксацию носителей на поверхности, что в свою очередь снижает степень спиновой поляризации носителей, инжектированных в полупроводниковую структуру $[8,9]$.

В настоящей работе исследовано влияние на спиновую инжекцию и циркулярно поляризованную люминесценцию обработки поверхности слоя GaAs в паpax селена для снижения дефектности границ раздела ферромагнитный металл/туннельно-тонкий диэлектрик/полупроводник в спиновых светоизлучающих диодах на основе гетероструктур с квантовыми ямами (КЯ) InGaAs/GaAs. Ранее авторами работ $[10,11]$ была про- демонстрирована возможность существенного снижения плотности поверхностных электронных состояний в результате обработки GaAs в парах селена.

Светоизлучающие структуры были сформированы на подложке $n$-GaAs (100) (структура $A$ ) или $p$-GaAs (100) (структура $B$ ) методом газофазной эпитаксии и представляли собой эпитаксиальные слои с КЯ $\mathrm{GaAs} / \mathrm{In}_{0.22} \mathrm{Ga}_{0.78} \mathrm{As}$. Квантовая яма толщиной $10 \mathrm{~nm}$ заращивалась покровным слоем GaAs толщиной $100 \mathrm{~nm}$ для структуры $A$ и $200 \mathrm{~nm}$ для структуры $B$. Согласно ранее полученным результатам $[12,13]$, диоды подобной конструкции реализуют спиновую инжекцию неосновных носителей заряда. Схемы структур представлены на вставке к рис. 1.

После роста поверхность светоизлучающих структур подвергалась отжигу при температуре $330-350^{\circ} \mathrm{C}$ в парах селена (парциальное давление составило $1.3 \mathrm{~Pa}$ ) в течение $5 \mathrm{~min}$. Отжиг проводился в вакуумной установке, в квазизамкнутом объеме. В результате отжига протекает реакция гетеровалентного замещения атомов As атомами Se с образованием слоя $\mathrm{Ga}_{2} \mathrm{Se}_{3}$ толщиной $7 \pm 2 \mathrm{~nm}[10,11]$.

Согласно [11], подобная обработка позволяет понизить плотность поверхностных электронных состояний в GaAs. Помимо обработанных структур также формировались контрольные образцы, которые отличались от исследованных только отсутствием обработки поверхности в парах селена.

Пленки $\mathrm{Ga}_{2} \mathrm{Se}_{3}$ были исследованы на рентгеновском дифрактометре Shimadzu 7000 с использованием $\mathrm{Cu} K_{\alpha^{-}}$ излучения. Для исключения из дифракционного спектра линий от подложки GaAs (100), влияющей на расчет дифракционных параметров исследуемой струк- 
туры, образец поворачивали вокруг его нормали так, чтобы направление максимального угла разориентации между кристаллографической плоскостью GaAs (100) и плоскостью поверхности образца было близко к нормальному по отношению к плоскости падающего и дифрагированного пучков.

Для формирования спиновых светоизлучающих диодов на поверхность структур методом электроннолучевого испарения наносились слой диэлектрика $\mathrm{Al}_{2} \mathrm{O}_{3}$ толщиной $1 \mathrm{~nm}$ и контакт Шоттки на основе сплава $\mathrm{Co}_{45} \mathrm{Pt}_{55}$ (толщина $8 \mathrm{~nm}$ ) [12]. Температура нанесения составляла $200^{\circ} \mathrm{C}$. Туннельно-тонкий слой $\mathrm{Al}_{2} \mathrm{O}_{3}$ служил диффузионным барьером для атомов Со [13], а также выполнял функцию повышения поверхностного сопротивления контакта, что является необходимым условием для спиновой инжекции [1-3]. К обратной стороне структур формировался омический контакт путем искрового вжигания $\mathrm{Sn}$ - (для $n$-GaAs) или Inфольги (для $p$-GaAs). Операция формирования спиновых светоизлучающих диодов завершалась процессами травления меза-структур диаметром 500 $\mu \mathrm{m}$.

На сформированных диодах были исследованы вольтамперные характеристики (BAX), а также электролюминесценция (ЭЛ). Температура исследований ВАХ и ЭЛ составляла $77 \mathrm{~K}$. Для измерения степени циркулярной поляризации $\left(P_{\mathrm{EL}}\right)$ вводилось внешнее магнитное поле, направленное перпендикулярно поверхности структур. Значение степени циркулярной поляризации рассчитывалось по формуле [1]:

$$
P_{\mathrm{EL}}=\frac{I\left(\sigma^{+}\right)-I\left(\sigma^{-}\right)}{I_{\mathrm{EL}}},
$$

где $P_{\mathrm{EL}}-$ степень циркулярной поляризации ЭЛ, $I_{\mathrm{EL}}=I\left(\sigma^{+}\right)+I\left(\sigma^{-}\right)-$интенсивность ЭЛ, $I\left(\sigma^{+}\right)$и

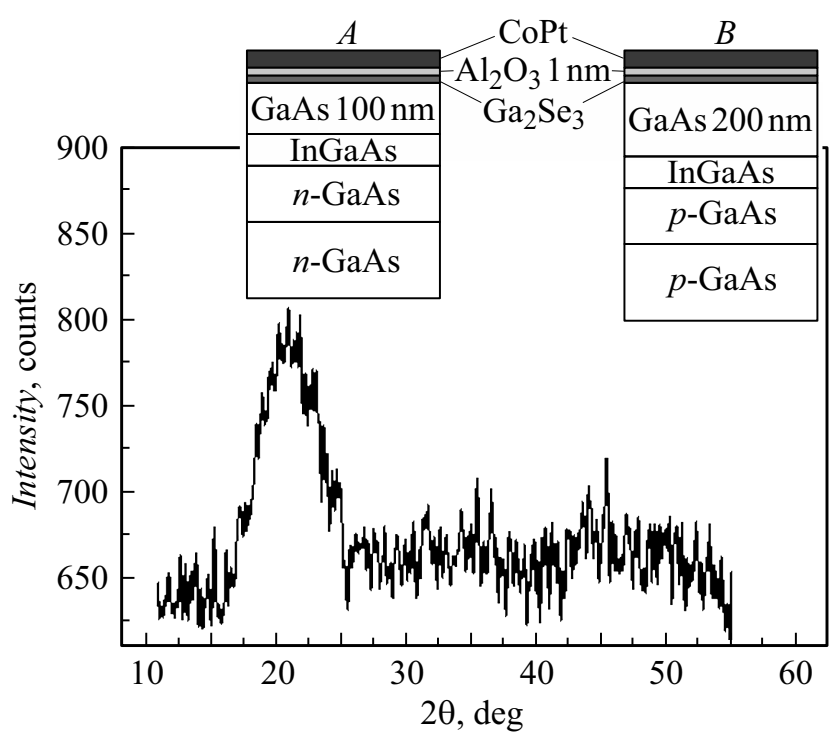

Рис. 1. Дифрактограмма образца $B$ перед нанесением слоев $\mathrm{Al}_{2} \mathrm{O}_{3} / \mathrm{CoPt}$. На вставке показана схема структур для исследования.

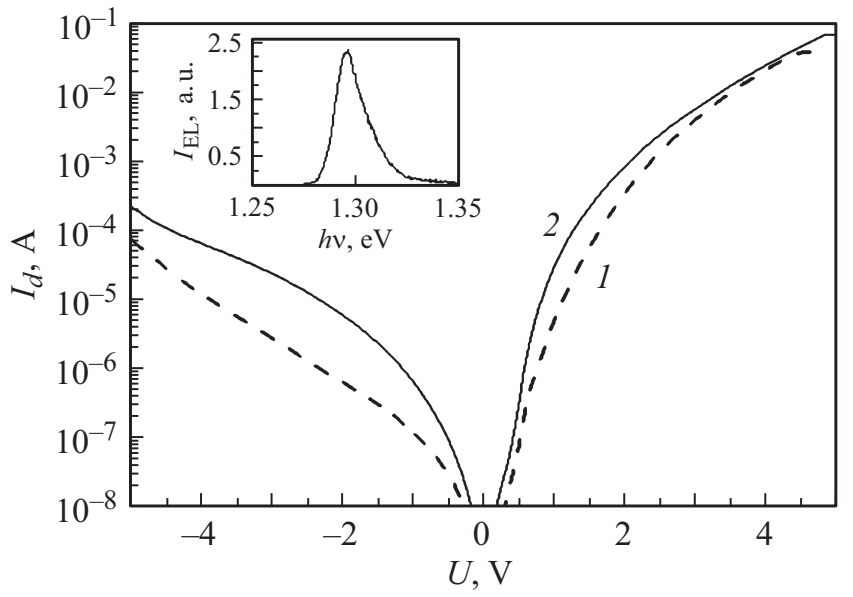

Рис. 2. Вольт-амперные характеристики, измеренные при $77 \mathrm{~K}$ для обработанного (1) и контрольного диода (2) на основе структуры $B$. На вставке показан спектр электролюминесценции диода $B$, измеренный при $77 \mathrm{~K}$.

$I\left(\sigma^{-}\right)$- компоненты интенсивности ЭЛ, поляризованные по правому и левому кругу соответственно [12].

На рис. 1 показана дифрактограмма образца $B$, поверхность которого была обработана в парах селена. В спектре виден широкий пик с максимумом при $2 \theta \approx 21^{\circ}$. На дифрактограмме контрольной структуры с необработанной поверхностью данный пик отсутствует, что позволяет связать его с формированием слоя $\mathrm{Ga}_{2} \mathrm{Se}_{3}$ в приповерхностной области образца в результате обработки в парах халькогена. Положение пика хорошо согласуется с данными работы [14], в которой проводились рентгенодифракционные исследования пленок $\mathrm{Ga}_{2} \mathrm{Se}_{3}$. Отметим, что подобный вид спектра дифрактограмм характерен для сильно разупорядоченной пленки $\mathrm{Ga}_{2} \mathrm{Se}_{3}$, подобный вывод относительно кристаллического качества $\mathrm{Ga}_{2} \mathrm{Se}_{3}$ был сделан и в [14].

На рис. 2 представлены ВАХ, измеренные для обработанного и контрольного диодов на основе структуры $B$ (кривые 1 и 2 соответственно). Наличие слоя $\mathrm{Ga}_{2} \mathrm{Se}_{3}$ вносит некоторые изменения в BAX, но существенной модификации механизма токопереноса, вероятно, не происходит. Можно отметить некоторое повышение сопротивления в структурах со слоем $\mathrm{Ga}_{2} \mathrm{Se}_{3}$, что может быть связано с вкладом сопротивлений на гетеропереходах металл $/ \mathrm{Al}_{2} \mathrm{O}_{3} / \mathrm{Ga}_{2} \mathrm{Se}_{3}$ и $\mathrm{Ga}_{2} \mathrm{Se}_{3} / \mathrm{GaAs}$. Для диодов на основе структуры $A$ были отмечены аналогичные тенденции, а именно повышение последовательного сопротивления структуры, обработанной в парах $\mathrm{Se}_{2}$, с сохранением общего вида ВАХ для исследованной и контрольной структур (не приведено).

На рис. 3 представлены зависимости степени циркулярной поляризации от магнитного поля, измеренные для диодов на основе структуры $A$ (кривые 1 и 2) и структуры $B$ (кривые 3 и 4 ). Кривые 1 и 3 соответствуют диодам, подвергнутым обработке в парах селена перед нанесением контактных слоев, кривые 2 и 4 - контроль- 

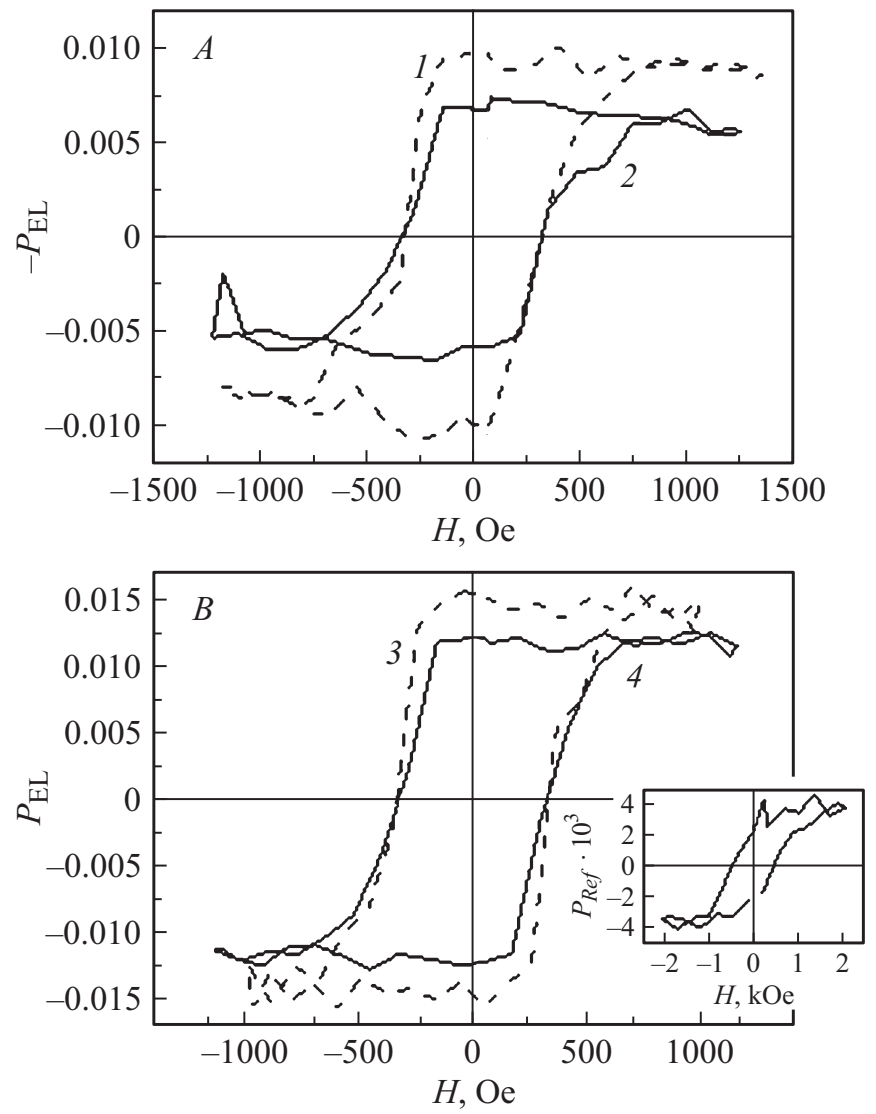

Рис. 3. Магнитополевые зависимости степени циркулярной поляризации электролюминесценции, измеренные при $77 \mathrm{~K}$ для диода на основе структуры $A(1,2)$ и для диода на основе структуры $B(3,4)$. Кривые 1,3 соответствуют структурам с поверхностью, обработанной в парах $\mathrm{Se}_{2}$, кривые 2,4 - контрольным диодам. На вставке показана зависимость степени циркулярной поляризации света, отраженного от поверхности пленки CoPt, от магнитного поля, в которое помещена структура с пленкой. Длина волны света $0.95 \mu \mathrm{m}$.

ным диодам. Вид магнитополевых зависимостей $P_{\mathrm{EL}}$ подобен кривым намагничивания слоев $\mathrm{CoPt}$, а регистрируемое значение обусловлено процессами, протекающими при инжекции спин-поляризованных носителей [12]. Видно, что как для спиновой инжекции электронов, так и для спиновой инжекции дырок обработка поверхности в парах селена приводит к повышению степени циркулярной поляризации ЭЛ в режиме остаточной намагниченности CoРt-контакта примерно в 1.3 раза. Отметим, что для одной и той же структуры условия нанесения $\mathrm{Al}_{2} \mathrm{O}_{3}$ и металлического контакта, параметры покровного слоя и активной области совпадали. Единственным отличием для диодов (ср. кривые 1 и 2, а также кривые 3 и 4 на рис. 3) является обработка поверхности перед нанесением контакта в парах селена. Поэтому повышение $P_{\mathrm{EL}}$ следует связывать с формированием под диэлектрической пленкой слоя $\mathrm{Ga}_{2} \mathrm{Se}_{3}$.

Перейдем к обсуждению результатов. Регистрируемое в эксперименте значение степени циркулярной поля- ризации ЭЛ определяется степенью спиновой поляризации носителей в слое CoPt (одинаковом для всех структур), процессами спиновой релаксации носителей при инжекции через гетерограницы структуры, а также в ходе переноса и излучательной рекомбинации в КЯ. Дополнительный вклад в $P_{\mathrm{EL}}$ вносит излучение КЯ, отраженное от намагниченного CoPt-контакта. Этот вклад был учтен путем измерений степени циркулярной поляризации, возникающей у неполяризованного света после его отражения от намагниченного слоя $\mathrm{CoPt}$ (вставка на рис. 3). При оценке влияния отражения на измеряемое значение $P_{\mathrm{EL}}$ следует учесть, что доля отраженного света в суммарном излучении диода не превышает 33\% (50\% излучения КЯ испускается со стороны подложки и не взаимодействует с $\mathrm{CoPt}$, еще $17 \%$ излучения [15] проходит через полупрозрачный CoPt-электрод и не регистрируется детектором). Поэтому максимальный вклад спин-зависимого отражения в значение $P_{\mathrm{EL}}$ оценивается величиной $\sim 0.16 \%$, что значительно меньше измеренного значения поляризации ЭЛ $\left(P_{\mathrm{EL}} \sim 1 \%\right)$. Спиновая релаксация носителей в КЯ не приводит к существенному снижению $P_{\mathrm{EL}}$ в силу того, что рекомбинационное время носителей в напряженных квантовых ямах InGaAs меньше или сопоставимо с временем спиновой релаксации [16,17]. Влияние на степень поляризации оказывает спиновая релаксация носителей при переносе к активной области [18]. Но этот процесс зависит только от толщины покровного слоя GaAs, и для структур с одинаковой толщиной указанного слоя (с пассивацией и без) изменение спиновой поляризации одинаковое. Таким образом, процессом, эффективность которого может меняться в результате обработки поверхности структур в парах селена, является спиновая релаксация носителей при переносе через границы между металлом, диэлектриком и полупроводником. Поэтому показанное на рис. 3 повышение степени поляризации в структурах $\mathrm{CoPt} / \mathrm{Al}_{2} \mathrm{O}_{3} / \mathrm{Ga}_{2} \mathrm{Se}_{3} / \mathrm{GaAs}$ по сравнению с таковой для структур $\mathrm{CoPt} / \mathrm{Al}_{2} \mathrm{O}_{3} / \mathrm{GaAs}$ связывается с уменьшением спиновой релаксации в приконтактной области, вызванным пассивацией поверхностных состояний слоем $\mathrm{Ga}_{2} \mathrm{Se}_{3}$. Несмотря на то что структура слоя $\mathrm{Ga}_{2} \mathrm{Se}_{3}$ является сильно разупорядоченной (по данным рентгеновской дифракции, представленным на рис. 1), эффект пассивации поверхности GaAs приводит к уменьшению плотности поверхностных состояний на границе раздела. В результате при переносе носителей через гетерограницу сохраняется более высокая степень спиновой поляризации, что и вызывает повышение измеряемого значения $P_{\mathrm{EL}}$. Наблюдаемый нами эффект повышения степени поляризации ЭЛ имеет ту же природу, что и обнаруженный в работе [8] эффект увеличения $P_{\mathrm{EL}}$ спинового светоизлучающего диода при повышении однородности границы раздела металла и полупроводника. Отличием нашей работы от [8] является применение метода пассивации поверхности (обработка в парах $\mathrm{Se}$ ), в то время как в [8] повышение качества границы достигнуто изменением метода нанесения (переход с 
магнетронного распыления на электронно-лучевое испарение) и серией постростовых отжигов.

Работа выполнена при поддержке РФФИ (16-07-01102a) и государственного задания № $16.7443 .2017 / Б Ч$.

\section{Список литературы}

[1] Holub M., Bhattacharya P. // J. Phys. D: Appl. Phys. 2007. V. 40. P. R179-R203.

[2] Nishizawa N., Nishibayashi K., Munekata H. // Appl. Phys. Lett. 2014. V. 104. P. 111102.

[3] Maekawa S. Concepts in spin electronics. N.Y.: Oxford University Press, 2006. 398 p.

[4] Аронов А.Г., Пикус Г.Е. // ФТП. 1976. Т. 10. В. 6. С. $1177-$ 1179.

[5] Salis G., Wang R., Jiang X., Shelby R.M., Parkin S.S.P., Bank S.R., Harris J.S. // Appl. Phys. Lett. 2005. V. 87. P. 262503.

[6] Родерик Э.Х. Контакты металл-полупроводник. М.: Радио и связь, 1982. $209 \mathrm{c.}$

[7] Ускова Е.А., Дорохин М.В., Звонков Б.Н., Дёмина П.Б., Малышева Е.И., Питиримова Е.А., Гильмутдинов Ф.З. // Поверхность. Рентгеновские, синхротронные и нейтронные исследования. 2006. № 2. С. 89-95.

[8] Barate P., Liang S., Zhang T.T., Frougier J., Vidal M., Renucci P., Devaux X., Xu B., Jaffres H., George J.M., Marie X., Hehn M., Mangin S., Zheng Y., Amand T., Tao B., Han X.F., Wang Z., Lu Y. // Appl. Phys. Lett. 2014. V. 105. P. 012404.

[9] Sato S., Nakane R., Hada T., Tanaka M. // Phys. Rev. B. 2017. V. 96. P. 235204

[10] Буданов А.В., Агапов Б.Л., Болдырева Я.А., Стрыгин В.Д., Татохин E.A. // Поверхность. Рентгеновские, синхротронные и нейтронные исследования. 2012. № 1. С. 21-27.

[11] Безрядин Н.Н., Котов Г.И., Арсентьев И.Н., Власов Ю.Н., Стародубцев А.А. // ФТП. 2012. Т. 46. В. 11. С. 756-759.

[12] Здоровейщев А.В., Дорохин М.В., Демина П.Б., Кудрин А.В., Вихрова О.В., Ведь М.В., Данилов Ю.А., Ерофеева И.В., Крюков Р.Н., Николичев Д.Е. // ФТП. 2015. T. 49. B. 12. C. $1649-1653$.

[13] Бобров А.И., Данилов Ю.А., Дорохин М.В., Здоровейщев А.В., Малехонова Н.В., Малышева Е.И., Павлов Д.А., Сайед $C$. // Поверхность. Рентггеновские, синхротронные и нейтронные исследования. 2015. № 7. С. 57-60.

[14] Afifi M.A., Bekheet A.E., El-Shair H.T., Zedan I.T. // Physica B. 2003. V. 325. P. 308-318.

[15] Кудрин А.В., Дорохин М.В., Здоровейщев А.В., Дёмина П.Б., Вихрова О.В., Калентьева И.Л., Ведь М.В. // ФТТ. 2017. T. 59. B. 11. C. 2203-2205.

[16] Salis G., Wang R., Jiang X., Shelby R.M., Parkin S.S.P., Bank S.R., Harris J.S. // Appl. Phys. Lett. 2005. V. 87. P. 262503.

[17] Liang S.H., Zhang T.T., Barate P., Frougier J., Vidal M., Renucci P., Xu B., Jaffres H., George J.-M., Devaux X., Hehn M., Marie X., Mangin S., Yang H.X., Hallal A., Chshiev M., Amand T., Liu H.F., Liu D.P., Han X.F., Wang Z.G., Lu Y. // Phys. Rev. B. 2014. V. 90. P. 085310.

[18] Дорохин М.В., Ведь М.В., Дёмина П.Б., Здоровейщев А.В., Кудрин А.В., Рыков А.В., Кузнецов Ю.М. // ФТТ. 2017. T. 59. B. 11. C. $2135-2151$. 